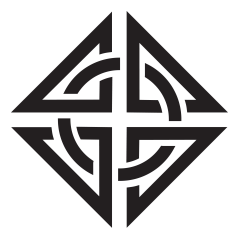

SCIENTIA
Sharif University of Technology

Scientia Iranica

Transactions F: Nanotechnology

www.scientiairanica.com

\title{
Neurotoxicity of pre-incubated alpha-synuclein with neutral nanoliposomes on PC12 and SHSY5Y cell lines
}

\author{
F. Aliakbari ${ }^{a, b, c}$, A.A. Shabani ${ }^{b, *}$, H. Bardania ${ }^{d}$, H.A. Eslampanah Seyedic, \\ H. Mohammad-Beigi ${ }^{\mathrm{e}}$, A. Tayaranian Marvian ${ }^{\mathrm{c}}$, M. Nasouti ${ }^{\mathrm{c}}$, A.A. Vafaei ${ }^{\mathrm{f}}$, \\ S.A. Shojaosadati ${ }^{\mathrm{g}}$, A.A. Saboury ${ }^{\mathrm{h}}$, G. Christiansen ${ }^{\mathrm{i}}$ and D. Morshedi ${ }^{\mathrm{c}, *}$ \\ a. Student Research Committee, School of Medicine, Semnan University of Medical Sciences, Semnan, Iran. \\ b. Department \& Center for Biotechnology Research, School of Medicine, Semnan University of Medical Sciences, Semnan, Iran. \\ c. Bioprocess Engineering Department, Institute of Industrial and Environmental Biotechnology, National Institute of Genetic \\ Engineering and Biotechnology, Tehran, Iran. \\ d. Cellular and Molecular Research Center, Yasuj University of Medical Sciences, Yasuj, Iran. \\ e. Interdisciplinary Nanoscience Centre (iNANO) and Department of Molecular Biology and Genetics, Aarhus University, Gustav \\ WiedsVej 14, DK-8000 Aarhus C, Denmark. \\ f. Laboratory of Learning and Memory, Research Center and Department of Physiology, School of Medicine, Semnan University of \\ Medical Sciences, Semnan, Iran. \\ g. Biotechnology Group, Faculty of Chemical Engineering, Tarbiat Modares University, Tehran, Iran. \\ $\mathrm{h}$. Institute of Biochemistry and Biophysics (IBB), University of Tehran, Tehran, Iran. \\ i. Department of Biomedicine, Aarhus University, 8000 Aarhus C, Denmark.
}

Received 13 September 2016; received in revised form 4 October 2016; accepted 8 November 2016

\author{
KEYWORDS \\ Alpha-synuclein; \\ Amyloid-related \\ diseases; \\ Fibrillation; \\ Nanoliposome; \\ Neurotoxicity; \\ Parkinson's disease.
}

\begin{abstract}
Alpha-synuclein ( $\alpha$-Syn) is a protein with high tendency to convert into toxic aggregates that are involved in Parkinson's Disease (PD). The conversion of $\alpha$-Syn into toxic aggregates may associate with bio-membranes and the interaction between $\alpha$-Syn and bio-mimic liposomes can trigger the neurotoxicity. Some inhibitors of $\alpha$-Syn aggregation are challengeable drugs. Using nano carriers such as nanoliposomes may overcome such challenges. Nevertheless, there are few studies on nanoliposomes effects on neuronal cells and $\alpha$-Syn. Herein, we investigated the neurotoxicity and fibrinogenesis of neutral charged nanoliposomes. Thin layer evaporation method and hydration method was employed to formulate the nanoliposomes from Dipalmitoylphosphatidylcholine to the size of $\leq 100 \mathrm{~nm}$. Fibrillation and cytotoxicity of $\alpha$-Syn treated with nanoliposome were measured. Neither neurotoxicity nor fibrillation was observed when $\alpha$-Syn treated with different concentrations of nanoliposome. These results well indicate that nanoliposome at the concentrations required for drug delivery not only is able to prevent fibrillation process, but also has no considerable toxic effects on the cells.

(C) 2017 Sharif University of Technology. All rights reserved.
\end{abstract}

\section{Introduction}

Proteins misfolding and aggregation are pathognomonic for nearly all age-related neurodegenerative

*. Corresponding authors. Tel.: +98 23-33654187 (A.A. Shabani); +9821-44878423 (D. Morshedi)

E-mail addresses: shabani@semums.ac.ir (A.A. Shabani); morshedi@nigeb.ac.ir (D. Morshedi)

doi: $10.24200 /$ sci.2017.4419 diseases, such as Parkinson's Disease (PD), Alzheimer's Disease (AD), and Lewy body with dementia, in which the formation of proteins aggregation has been identified as amyloid fibrils $[1,2]$. The aggregation of $\alpha$ Syn, small (14 kDa) and highly conserved presynaptic protein $[3,4]$, has been identified to have a critical role in $\mathrm{PD}$ and other synucleinopathy diseases [57]. The conversion of soluble $\alpha$-Syn into insoluble well-ordered beta sheet structures is associated with 
the deposits known as Lewy bodies and Lewy neurites $[8,9]$.

$\mathrm{PD}$ is the second most common neurodegenerative disease, and so far, various studies have reported on the role of $\alpha$-Syn in the initiation and spreading of neurodegeneration in $\mathrm{PD}$. The degeneration of dopaminergic neuronal cells has been shown to be connected with the development of $\alpha$-Syn fibrillation [10]. Hence, there is a considerable interest in inhibiting $\alpha$-Syn fibril formation, which can be a virtuous avenue to impede the development of PD [11-13].

Nowadays, nanoparticles are immensely considered a promising strategy in drug delivery systems [14]. Remarkably, engineered nanomaterials not only suggest novel structural, optical, and electronic properties in diagnostics and therapy of different diseases [15], but also deliver several functionalities due to their extended surface area, diverse surface chemistry, and unique pharmacokinetics $[15,16]$. In fact, these characteristics bring about mighty potency to increase the solubility, concerning the hydrophobic drugs and stability of both hydrophobic and hydrophilic drugs in the aqueous medium of the body, and carry them to the target tissue [17].

Liposomes, as a major class of macromolecular carriers, owing to several merits including biocompatibility, low immunogenicity, protecting cargo against enzymatic degradation, and easy surface modification, have been interestingly aimed at targeted delivery [18] . Moreover, the nature and structure of liposome, containing a core of aqueous solution with two layers of phospholipid, gives it a unique capacity to deliver both hydrophobic and hydrophilic drugs [15]. This means that nanoliposomes are significantly regarded as nano carriers with high capacity for encapsulation of drugs.

Nanoliposomes may themselves possess an aptitude to be utilized as a substance for disease treatment $[19,20]$. According to the estimations, less than half of the drugs used in the treatment of human diseases are hydrophobic with very low solubility in body fluids; thus, the requisite for a high dose and frequency of consumption is a challenge concerning the use of these drugs. Furthermore, sometimes, in order to raise the solubility of the drugs, chemical modification is required, causing side effects. In addition, a drug overdose and its high intake can affect non-target tissues [21,22]. Therefore, the use of nanoliposomes in overcoming such problems is applicable. So far, most reports corresponding to Food and Drug Administration (FDA) have confirmed that liposome-based drug have been focused on cancer treatment [23,24].

To date, some studies have been reported regarding the use of nanoparticles in amyloid diseases, PD and $\mathrm{AD}$, to alleviate toxicity in the course of fibrillation process $[25,26]$. Nanoliposomes are respectable candidates for drug delivery in amyloid diseases due to their phospholipid-based structure, compatibility with the body's system, and minute size, making them pass across blood brain barrier easily [27]. However, given the aggregated species of $\alpha$-Syn transferring from cell to cell, causing cell degeneration [28,29], assessment of nanoliposome impact on neurons cells sounds essential before being used as a drug carrier.

Hence, considering that few reports are available on the effects of nanoparticles on neuronal cells and $\alpha$-Syn, the aim of this study is to investigate the cytotoxic effects of neutral charged nanoliposome in different concentrations $(35,70,140,280,560,1120$, 1500 , and $3000 \mu \mathrm{M}$ ) alone and when pre-incubated with $\alpha$-Syn on dopaminergic cell lines, PC12 and SHSY 5Y. The nanoliposome was formulated from Dipalmitoylphosphatidylcholine (DPPC) with the size of $\leq 100 \mathrm{~nm}$, and its effect on the $\alpha$-Syn fibrillation was assessed. Subsequently, the neurotoxicity of $\alpha$ Syn in the presence of nanoliposomes was monitored using MTT and LDH assays. Results extracted from this study showed that neutrally-charged nanoliposome has an acceptable potential as a drug carrier in the neurodegenerative disorders associated with $\alpha$-Syn aggregation. Moreover, having high capacity to transfer both hydrophobic and hydrophilic small molecules, the neutrally-charged nanoliposome can trigger $\alpha$-Syn fibrillation and also decrease the cell death resulting from such protein aggregated species.

\section{Experimental procedure}

\subsection{Reagents}

DPPC and Mini-Extruder were prepared from Avanti Polar Lipids, Inc. (USA). Thioflavin T (ThT), Congo red, and 3-(4,5-dimethylthiazol-2-yl)-2,5-diphenyltetr azolium bromide (MTT) were purchased from SigmaAldrich (USA). LDH was acquired from Pishtazteb Co. (Iran). PC12 and SHSY5Y cell lines were acquired from Pasteur Institute (Iran). All salts and organic solvents were purchased from Merck (Darmstadt, Germany). The cell culture mediums (DMEM high glucose and DMEM-F12) and antibiotics were purchased from GibcoBRL (Life Technologies, Paisley, Scotland). Fetal bovine serum (FBS) was from Biosera (England).

\subsection{Nanoliposome formulation and characterization}

Thin layer evaporation and hydration procedures were employed to formulate the liposomes [30]. In brief, DPPC was dissolved in $1 \mathrm{~mL}$ chloroform and the thin layer of lipid was arranged using rotary evaporator with 400 Mbar pressure at $37^{\circ} \mathrm{C}$ at $150 \mathrm{rpm}$ shaking in a round bottom flask. In the following, the lipid layer was hydrated with Phosphate Buffer Saline (PBS, pH 7.4) at $50^{\circ} \mathrm{C}$ for approximately $2 \mathrm{~h}$. In order to convert the Multi-Vesicular Vesicles (MVV) and Multi-Lamellar 
Vesicles (MLV) to smaller vesicles, including Large Unilamellar Vesicles (LUV) and Small Unlilamellar Vesicles (SUV), the material was then sonicated using UP400S Ultrasonic processor (hielscher, Germany) for four times (Cycle 0.5, Amplitude 60\%), each for 45 seconds with an internal rest of 30 seconds. Then, the Mini-Extruder set equipped by $100 \mathrm{~nm}$ filter was employed to formulate SUV in a size of $\approx 100 \mathrm{~nm}$. In the last step, size, surface charge, and form of the formulated nanoliposomes were evaluated using Zeta seizer (MAlVER, UK) and Transmission Electron Microscopy (TEM) (JEM-1010; JEOL, Tokyo, Japan).

\subsection{Transmission electron microscopy}

A $5 \mu \mathrm{L}$ sample of nanoliposome was relocated to a carbon-coated, glow-discharged 400-mesh grid for 30 seconds. The grids were then rinsed by two droplets of double distilled water, and stained with $1 \%$ phosphotungstic acid ( $\mathrm{pH}$ 6.8), and blotted dry. The samples were processed for microscope observation (JEM-1010; JEOL, Tokyo, Japan) working with $60 \mathrm{kV}$ and the images were obtained using an Olympus KeenView G2 camera.

\subsection{Protein expression and purification}

The pET11-D plasmid, containing human $\alpha$-Syn cDNA, was transformed to Escherichia coli BL21 (DE3) strain. The transformed cultures were grown overnight at $37^{\circ} \mathrm{C}$ in $1 \mathrm{~L}$ of LB medium (10 gr Tryptone, 5 gr Yeast Extract and $10 \mathrm{gr} \mathrm{NaCl}$ per liter) containing $100 \mu \mathrm{g} / \mathrm{mL}$ of kanamycin. The sub-culture of the grown bacteria was prepared and protein expression was carried out using auto-induction according to the protocol described elsewhere [31]. To extract protein, cells were centrifuged for $20 \mathrm{~min}$ at $3500 \mathrm{rpm}$ at $4^{\circ} \mathrm{C}$. The pellet obtained by $1 \mathrm{~L}$ culture was then resuspended in $100 \mathrm{~mL}$ osmotic shock buffer (30 mM Tris-HCl, 40\% sucrose, 2 mM EDTA, pH 7.2) and incubated for 10 min at room temperature followed by centrifugation for $30 \mathrm{~min}$ at $9000 \mathrm{~g}$ at $20^{\circ} \mathrm{C}$. The acquired pellet was resuspended in $90 \mathrm{~mL}$ ice-cold deionized water followed by adding $40 \mu \mathrm{L}$ of saturated $\mathrm{MgCl}_{2}$ and incubated on ice for $3 \mathrm{~min}$. Then, the material was centrifuged for $20 \mathrm{~min}$ at $9000 \mathrm{~g}$ at $4^{\circ} \mathrm{C}$, and the supernatant was collected. Precipitation of the supernatant was carried out by titration with $1 \mathrm{M} \mathrm{HCl}$ to $\mathrm{pH} 3.5$ and incubated for $5 \mathrm{~min}$. The supernatant was then collected by centrifugation for $20 \mathrm{~min}$ at $9000 \mathrm{~g}$ at $4^{\circ} \mathrm{C}$ and titrated to $\mathrm{pH} 7.5$ with the drop-wise addition of $1 \mathrm{M} \mathrm{NaOH}$. The extracted protein was filtered through $0.45 \mu \mathrm{m}$ filter and loaded onto a Q-Sepharose column (HiTrap Q H P), which was pre-equilibrated with $20 \mathrm{mM}$ Tris$\mathrm{HCl}$ ( $\mathrm{pH} 7.5)$. The column was rinsed with $0.1 \mathrm{M} \mathrm{NaCl}$ in buffer with three column volumes, $\alpha$-Syn was eluted with a $\mathrm{NaCl}$ gradient from 0.1-0.5 M, and the collected purified protein was dialyzed against deionized water.
SDS - Polyacrylamide Gel Electrophoresis (with $13 \%$ resolving gels) was employed to analyze the fractions. Finally, the purified $\alpha$-Syn was freeze dried and stored at $-20^{\circ} \mathrm{C}$ for the next steps.

\section{5. $\alpha-S y n$ fibrillation assay}

$\alpha$-Syn was dissolved in PBS buffer $(\mathrm{pH} 7.2)$ in a final concentration of $70 \mu \mathrm{M}$ supplemented by different concentrations of neutral charged nanoliposomes (35, $70,140,280,560,1120,1500$, and $3000 \mu \mathrm{M})$ in a final volume of $150 \mu \mathrm{L}$, added to each well of a 96well plate with a $3 \mathrm{~mm}$ diameter glass bead. A sample of $\alpha$-Syn without nanoliposome was considered as control. Plates were sealed with a crystal clear sealing tape (Hampton Research, Aliso Viejo, CA). The fibrillation process was conducted at $37^{\circ} \mathrm{C}$ with $300 \mathrm{rpm}$ orbital shaking. After a period of time, the fibril formation with or without nanoliposomes was assessed by standard tests including ThT and Congo red.

\subsection{Cell culture}

PC12 and SHSY5Y cell lines were cultured in DMEM high glucose and DMEM-F12, respectively, which were complemented with $100 \mathrm{u} / \mathrm{mL}$ penicillin, $100 \mu \mathrm{g} / \mathrm{mL}$ streptomycin, and $10 \% \mathrm{FBS}$, and incubated at $37^{\circ} \mathrm{C}$ in humidified atmosphere with $5 \% \quad \mathrm{CO}_{2}$ and $90 \%$ humidity. Then, the cells were subcultured in 96-well microliter plates for the toxicity assays.

\subsection{Toxicity assays}

In order to assess the cytotoxicity of different concentrations of nanoliposomes alone and when preincubated with $\alpha$-Syn on the cell lines, MTT and LDH assays were employed as follows:

\subsubsection{Cell viability assay}

To conduct MTT, 3-(4,5-dimethylthiazol-2-yl)-2,5-diphenyltetrazolium bromide, as a colorimetric assay for evaluating cell metabolic activity revealing cytotoxicity and cell viability, the cells were seeded with density of $3 \times 10^{4}$ and $6 \times 10^{4} \mathrm{cell} / \mathrm{ml}$ for PC12 and SHSY5Y, respectively, and incubated in a $\mathrm{CO}_{2}$ incubator for 24 $\mathrm{h}$ followed by treatment with different concentrations of nanoliposomes alone and when pre-incubated with $\alpha$-Syn $(10 \% \mathrm{v} / \mathrm{v})$. After that, the cultures were incubated in the same condition for more $24 \mathrm{~h}$. Then, the medium was removed, the wells were washed by PBS, a freshly medium complemented with $10 \%(\mathrm{v} / \mathrm{v})$ MTT stock solution (5 mg/mL in PBS) was added to each well, and the plates were incubated for $4 \mathrm{~h}$ in the dark. In the following, the insoluble purple formazan crystals, formed because of reducing the tetrazolium dye through cellular oxidoreductase, were dissolved in DMSO. The purple formazan product was then measured at $570 \mathrm{~nm}$ by Eliza reader (Expert 96, AsysHitch, Ec Austria) to reflect the number of 


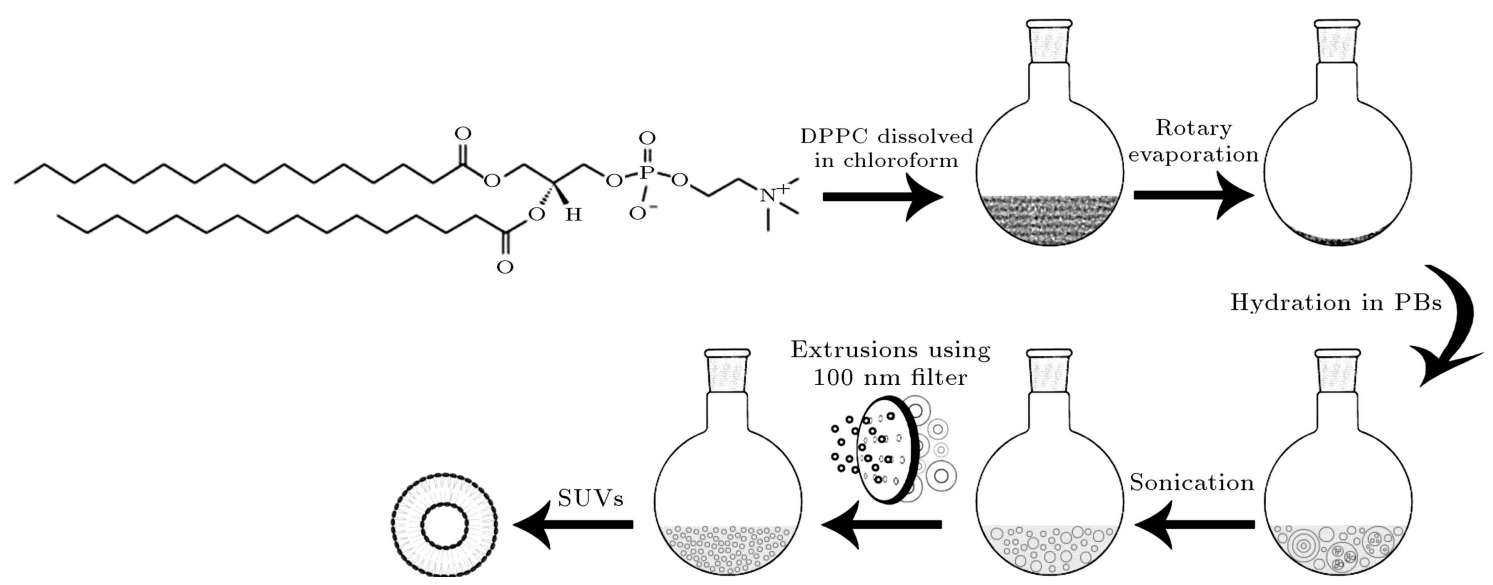

Figure 1. Schematic procedure to formulate neutrally-charged nanoliposome from DPPC using thin layer evaporation and hydration methods followed by sonication and extrusion.

viable cells present. The percentage of control cells was regarded as $100 \%$, and the percentage of viable cells was considered as follows:

Cell viability of the treated sample (\%)

$$
=\frac{\left(\operatorname{Abs}_{570}(\text { Treated cells })\right)}{\left(\operatorname{Abs}_{570}(\text { Control cells })\right)} \times 100 .
$$

\subsubsection{Lactate dehydrogenase release assay}

Lactate dehydrogenase (LDH) is a cytosolic enzyme present in most live cells, and this experiment quantitatively measures $\mathrm{LDH}$ released into the media from damaged cells as an indication of cytotoxicity. Here, according to the LDH cytotoxicity assay kit, extracellular $\mathrm{LDH}$ in culture media was measured using an enzymatic reaction that results in the reduction of substrate. In brief, following the treatment of cells and further incubation for $24 \mathrm{~h}$, a total of $100 \mu \mathrm{L}$ sample of growth media was collected and added to $1 \mathrm{~mL}$ of the arranged substrate from the kit. In the final step, the absorbance was measured at $340 \mathrm{~nm}$ using spectrophotometer $\left(\mathrm{T} 80^{+} \mathrm{UV} / \mathrm{VIS}, \mathrm{PG}\right.$ instruments Ltd, England) at $37^{\circ} \mathrm{C}$. The $\mathrm{LDH}$ reaction acts as follows:

$$
\begin{aligned}
& \left(\text { Pyruvate }+\mathrm{NADHA}+H^{+} \stackrel{\mathrm{LDH}}{\rightarrow}\right. \text { Lactate } \\
& \left.\quad+\mathrm{NAD}^{+}\right) .
\end{aligned}
$$

\subsection{Statistical analysis}

Statistical analysis was conducted using SPSS version 16.0. All experiments were carried out for three times, and the results were provided as means $\pm \mathrm{SD}$. One-way ANOVA and Unpaired Student's t-test were used to consider the statistical significance within the groups and between the groups, respectively. $P$ Values $<0.05$ were regarded as significant.

\section{Results and discussion}

\subsection{Nanoliposome preparation and characterization}

The neutrally-charged nanoliposome in a size of $\leq$ $100 \mathrm{~nm}$ diameter was formulated from DPPC using thin layer evaporation and hydration methods followed by means of sonication and mini-extruder set, as shown in Figure 1.

To characterize the formulated nanoliposome, DLS was employed to analyze the size and Poly dispersity Index (PdI). The particle size evaluated by DLS (z-average) based on number of particles was determined for nanoliposomes prepared from the neutral charged phospholipid as $71.37 \mathrm{~nm}$ (PdI 0.234), as shown in diagram (Figure 2(a)). Furthermore, the surface charge of nanoliposome was measured by $\zeta$ potential assessment. Results indicated $\zeta$ potential value of $-1.795 \pm 0.545 \mathrm{mV}$ for nanoliposome. As a result, we confirmed that nanoliposomes are neutrally charged. The outcomes of TEM analysis (Figure 2(b)) confirmed what was achieved by DLS analysis, and revealed the spherical and unilamellar morphology of the nanoliposomes. In addition, the results obtained from TEM analysis demonstrated that the sizes of nanoliposomes were nearly in the range of 60-90 nm.

The stability of nanoliposomes was assessed by evaluating the changes in the size of nanoliposomes throughout 21 days at $4^{\circ} \mathrm{C}$. No considerable evidence was observed in the change of nanoliposomes size where stored at $4^{\circ} \mathrm{C}$ over a period of 21 days (Table 1 ).

\subsection{Effect of the neutral charge nanoliposome on $\alpha-S y n$ fibrillation}

The molecular basis of PD appears to be tightly associated with the aggregation of $\alpha$-Syn into amyloid fibrils, which is believed to play an important role in $\mathrm{PD}$ and some other amyloid-related disorders [6, 3234]. Results obtained from the research on various cells 


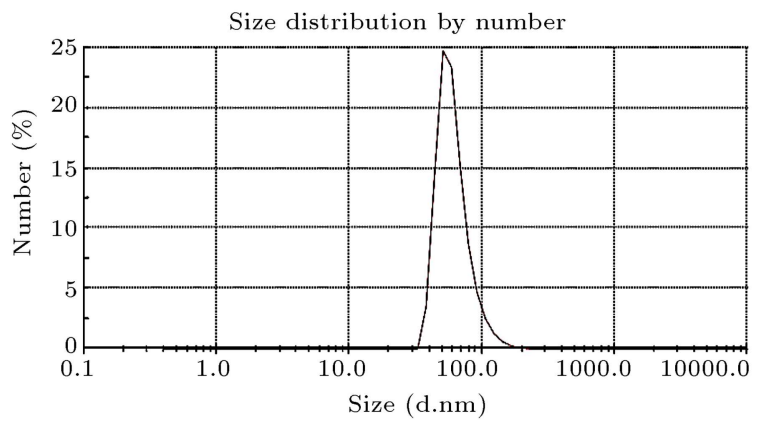

(a)

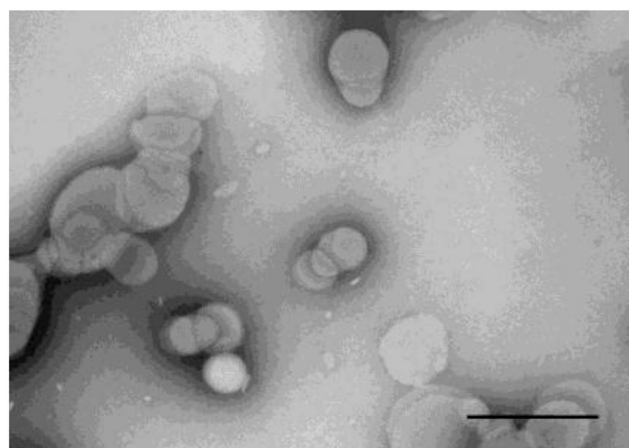

(b)

Figure 2. Size, charge, and morphology of nanoliposome formulated from DPPC were evaluated using DLS and TEM: (a) Size distribution by number for neutral charge nanoliposomes measured by dynamic light scattering, and (b) transmission electron microscopy image for nanoliposome (Scale bar, $200 \mathrm{~nm}$ ).

Table 1. The stability assessment of the nanoliposome size throughout 21 days at $4^{\circ} \mathrm{C}$ using DLS.

\begin{tabular}{ccc}
\hline \multirow{2}{*}{$\begin{array}{c}\text { Storage time } \\
\text { (day) }\end{array}$} & \multicolumn{2}{c}{$\begin{array}{c}\text { Nanoliposome derived } \\
\text { from }\end{array}$} \\
\cline { 2 - 3 } & SPPC $(\mathbf{n m})$ & PDI \\
\hline 0 & 71.37 & 0.23 \\
7 & 76.85 & 0.24 \\
14 & 98.52 & 0.23 \\
21 & 103.74 & 0.22 \\
\hline
\end{tabular}

and animal models offer that the prevention of amyloid aggregation is worthwhile to alleviate the symptoms of amyloidosis [35,36]. Accordingly, numerous studies have been reported concerning the compounds to inhibit and/or disaggregate $\alpha$-Syn aggregation, which could be considered a therapeutic strategy towards these neurodegenerative amyloid disorders. Some of the anti-aggregating components, which have so far been identified to have a potential use in the treatment of amyloidosis, include antibodies, synthetic peptides, chemically-synthesized compounds, small organic molecules, and heat shock proteins [37-41].

Recently, nanoparticles have been significantly considered in not only the study of protein aggregate recognition and destruction [42-43], but also in the realm of protein fibrillation [44-46] and inhibition of fibril formation [47]. According to previous studies, the interaction of nanoparticles with proteins can lead to perturbation of both protein structure and function. Nanoparticles' biophysicochemical properties, containing size, morphology, chemical composition, surface charge, and hydrophobicity, possess important roles in the fibrillation process through their impact on proteins conformation [46]. Therefore, a general trend of response in the fibrillation is not expected by dissimilar nanoparticles. It means that the interaction of nanoparticles and amyloid proteins might result in different outcomes, including inhibition or facilitation of amyloid formation, or even be ineffective.

Here, the formulated neutrally-charged nanoliposomes (as described in previous section) were applied to investigate the nanoliposomes impact on $\alpha$-Syn fibrillation using ThT fluorescence intensity, Congo red absorbance, and fluorescents microscopy images.

To determine the effect of nanoliposome on the protein fibrillation, $\alpha$-Syn was treated with different concentrations of nanoliposome and incubated for 24 and $48 \mathrm{~h}$ at $37^{\circ} \mathrm{C}$. Rate of $\alpha$-Syn fibrillation in the presence or absence of nanoliposome was measured based on the level of ThT fluorescence emission (Thioflavin T-binding assay) (Figure 3(a)). The emission of ThT fluorescence is relevant to $\beta$-sheet structure and fibril formation. The results indicated that nanoliposome almost permanently decreased $\alpha$-Syn fibrillation in a concentration-independent manner. In addition, for more control samples, the monomer of $\alpha$-Syn, monomer incubated with $3000 \mu \mathrm{M}$ of nanoliposome for $1 \mathrm{~min}$, $3000 \mu \mathrm{M}$ of nanoliposomes alone, $3000 \mu \mathrm{M}$ of nanoliposomes with ThT were assessed by the fluorimetry to evaluate whether they raise ThT emission and could interfere with the results or not. No emission was taken at $480 \mathrm{~nm}$ for each sample, indicating no interference of $\mathrm{ThT}$ with nanoliposome (data not shown). Congo red analysis also confirmed ThT results. As elucidated from Figure 3(b), a detectable red shift was observed in the $\alpha$-Syn incubated without nanoliposomes rather than the protein treated with nanoliposomes.

To analyze the morphology of $\alpha$-Syn aggregates with or without nanoliposomes, fluorescent microscopy images were taken after $24 \mathrm{~h}$ of incubation (Figure $3(\mathrm{c}))$. The noticeable $\alpha$-Syn fibril extensions were detected in the $\alpha$-Syn sample alone (Figure 3(c.1)), while the protein treated with nanoliposomes displayed lower fibrillation (Figure 3(c.2-9)) .

The neutral charge nanoliposomes formulated here demonstrated to have no inducing effect on the fibril formation. In fact, they were shown to have the potential to decrease such a phenomenon. However, there are still vague features in the field of interactions between nanoparticles and amyloid proteins. More 


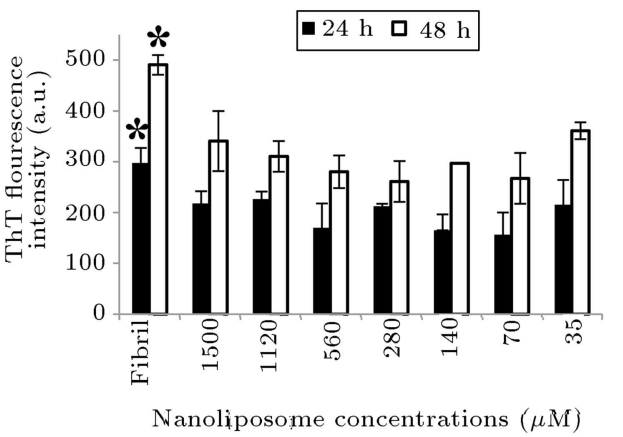

(a)
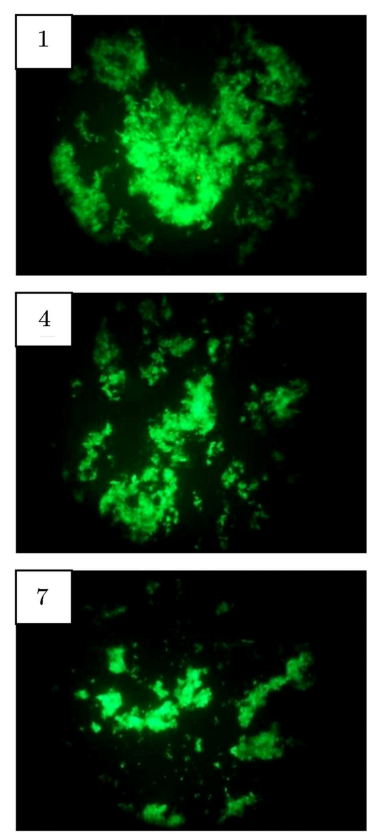
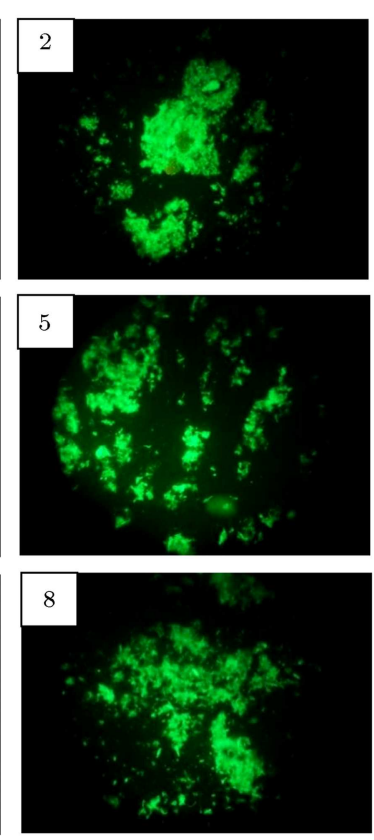

(c)

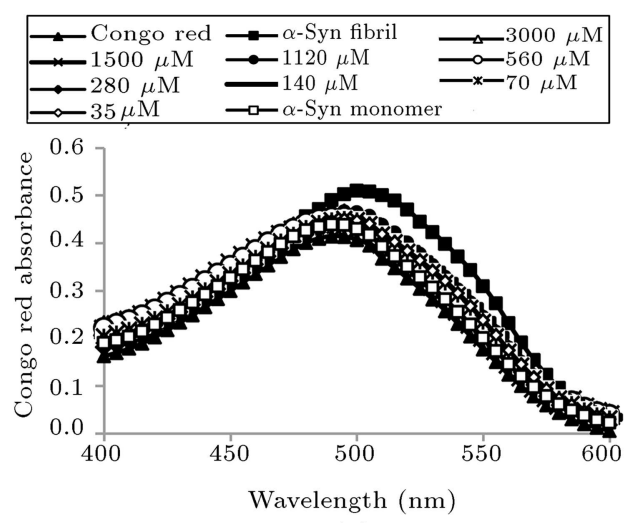

(b)
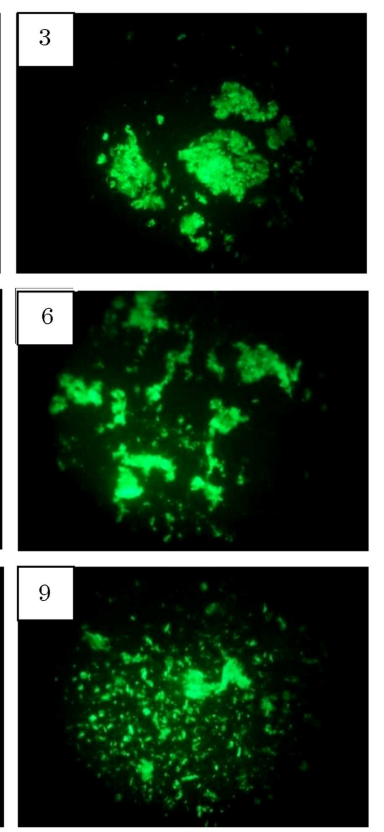

Figure 3. $\alpha$-Syn fibril formation assay in the absence or presence of different concentrations of nanoliposome using ThT fluorescence intensity, Congo red absorbance and fluorescence microscopy images: (a) ThT fluorescence intensity for $\alpha$-Syn incubated alone or with different concentrations of nanoliposome after 24 and 48 h of incubation, (b) Congo red spectra (400-600 nm) for monomer of $\alpha$-Syn and $\alpha$-Syn incubated alone or with different concentrations of nanoliposome after $24 \mathrm{~h}$ of incubation, and (c) fluorescence images taken from $\alpha$-Syn incubated alone or with different concentrations of nanoliposome after $24 \mathrm{~h}$ of incubation: (c.1) $\alpha$-Syn alone, (c.2-9) $\alpha$-Syn incubated with 35, 70, 140, 280, 560, 1120, 1500, and $3000 \mu \mathrm{M}$ of nanoliposomes, respectively. Results of $\alpha$-Syn incubated with different concentrations of nanoliposome are significantly dissimilar to those of controls ( $\alpha$-Syn incubated alone) (mean $\pm \mathrm{SD}, n=3, * p \leq 0.05$ ).

studies are required to elucidate the mechanism of fibril formation at the molecular level.

\subsection{Neurotoxicity of nanoliposomes and nanoliposomes pre-incubated with $\alpha-S y n$}

To investigate nanoliposomes toxicity as well as capability of nanoliposomes to hamper $\alpha$-Syn aggregatesmediated cellular toxicity, MTT and LDH assays were performed using PC12 and SHSY5Y cell lines.

MTT, a tetrazolium salt, is reduced into insoluble formazan crystals by mitochondrial dehydrogenase in living cells. At first, the cytotoxic potential of nanoliposome on PC12 and SHSY5Y cells was assessed.
Results indicated that nanoliposome had no considerable cytotoxic impact on the two kinds of cell lines in different concentrations ranging from $35-3000 \mu \mathrm{M}$ (Figure 4(a)). Nonetheless, the susceptibility of the cell lines seems to be slightly different from each other while being treated with nanoliposomes. In SHSY5Y cells, at the concentrations of 1500 and $3000 \mu \mathrm{M}$ of nanoliposomes, a slight enhancement was observed in cell proliferation. It can be presumed that this increase might be correlated to nanoliposomes' role as a scaffold, which leads to cell growth or as a nutrition source for cells. With this interpretation, it has been recently identified that oxidation of fatty acids is essential for 


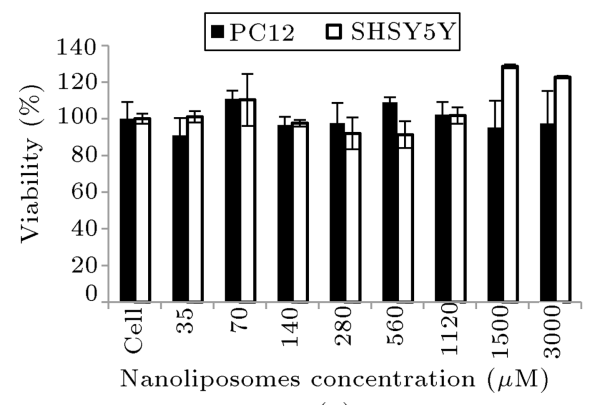

(a)

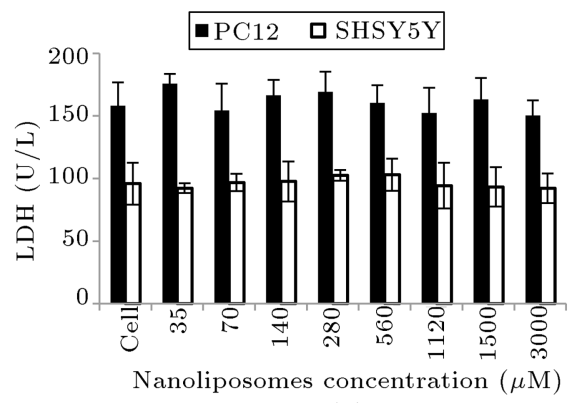

(b)

Figure 4. Neurotoxicity of varied concentrations of nanoliposome on the PC12 and SHSY5Y cell lines after $24 \mathrm{~h}$ of incubation: (a) The percentage of cell viability treated with nanoliposomes using MTT assay, and (b) measurement of released lactate dehydrogenase from cells (an indicator of cell membrane integrity) treated with nanoliposomes after $24 \mathrm{~h}$ of incubation.

malignant glioma cells (Glioma is of primary malignant brain tumor in adult) in which targeting this metabolic pathway leads to decreasing energy, and consequently reducing cell proliferation. In other words, besides glucose, the cancer cells use lipid for their respiratory activity $[48]$.

In the following, the neurotoxicity of $\alpha$-Syn preincubated with varied concentrations of nanoliposome was evaluated on both PC12 and SHSY5Y cell lines. $\alpha$-Syn aggregates showed to reduce the cell viability of PC12 and SHSY5Y cells with different rates, which validated the dissimilar susceptibility of two kinds of cell line (Figure 5(a) and Figure 6(a) and (b)). However, pre-incubation of $\alpha$-Syn with nanoliposome led to modulating the $\alpha$-Syn aggregates-mediated neurotoxicity towards lower cytotoxic effect.

Simultaneously, the LDH assay supported the results obtained from MTT for both experiments, including the neurotoxicity of nanoliposome alone (Figure 4(b)) and $\alpha$-Syn pre-incubated with nanoliposome (Figure 5(b)). LDH is assessing the integrity of cell membrane, indicating live cells. The cell membrane is the first part dealing with external agents and the main objective of toxic fibrils. The aggregates involve membrane disruption, and so the cytotoxicity is more observable in here. Results obtained here well highlight the safety of the formulated nanoliposomes on dopaminergic cell lines.

The toxic effects of nanoparticles on human health have been one of the chief concerns of nanoparticles applications [49]. The studies have well demonstrated that nanoparticles can influence biological behavior at the cellular and protein levels. Nanoparticles report to have carcinogenic effects, which lead to DNA impairment, and induce inflammatory lesions [50]. Therefore, there is an essential requisite to assess the toxicity of nanoparticles before applying them as safe components in medical and pharmaceutical industries. The cytotoxicity of nanoparticles is mainly associated with particle parameters containing size, shape, chemical composition (purity, electronic properties, or crystallinity), surface structure (surface coatings-inorganic or organic), charge, hydrophobicity, and aggregation behavior [51,52]. Nevertheless, biological factors, including type of cells, and culture circumstances, such as temperature, culture medium components and cell density, can affect cytotoxicity [52].

The surface charge seems to possess more complexity related to cytotoxicity compared with other factors such as size [53]. The cytotoxicity of liposomes has been shown to be connected with their charge and size [54]. Considering the similar size, neutral liposomes have been shown to have less toxicity than charged liposomes, whereas the positive types/cationic liposomes are more toxic than negative ones in cells [5457]. Cationic liposomes involved with reactive oxygen intermediates destroy plasma-membrane integrity, mitochondria, and lysosomes and increase the number of autophagosomes in contrast to anionic particles, resulting in intracellular damage $[52,56]$. Therefore, the toxicity of some formulated liposomes, especially that incorporating cationic agent is noticed as the major disadvantage in the medical application. However, in some cases, cationic liposomes have, in turn, been suggested to be an efficient tool for the selective delivery of antiangiogenic drugs to target tissue [58].

Since it has well been recognized that the terms of nanoliposomes formulation interfere with the cell cytotoxicity, the parameters, including kind of lipid, nature and amount of the charged component, and the liposome size, are vital to be considered to achieve nanoliposomes formulated with minimum toxicity [59]. Moreover, the amount and type of nanoliposome with the ratio of lipid to protein are involved in protein fibrillation [19,20]. Given that DPPC has been shown to have less toxic effect than other phospholipids, such as DMPC [59], in the present study, DPPC was utilized to formulate neutrally-charged nanoliposomes in order to assess nanoliposomes effect on the protein fibrillation and neuron toxicity. 


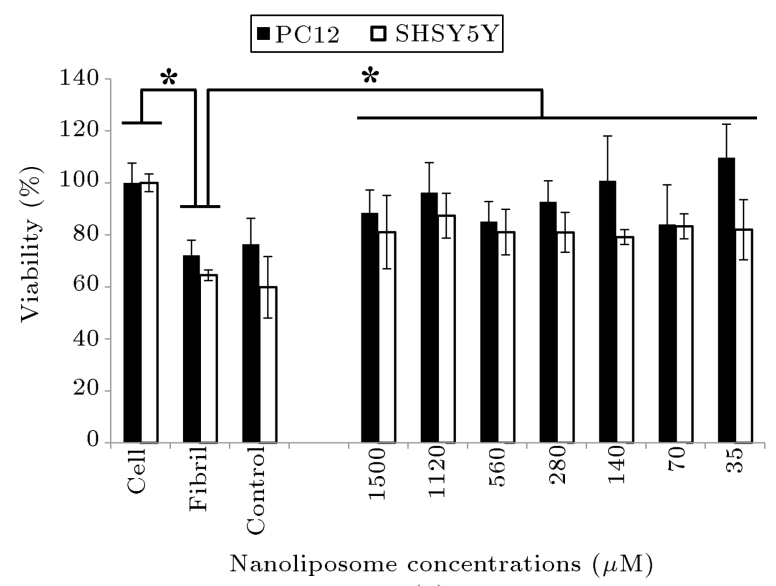

(a)

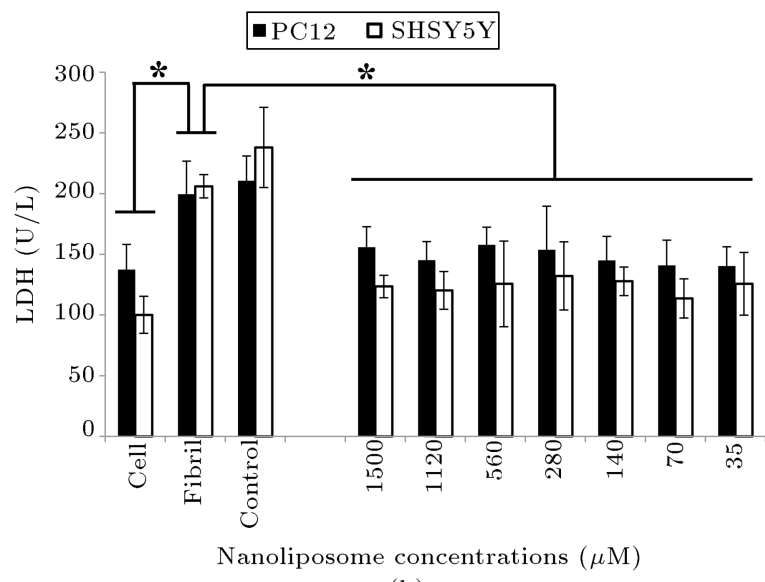

(b)

Figure 5. Neurotoxicity of $\alpha$-Syn pre-incubated with different concentrations of nanoliposomes on the PC12 and SHSY $5 Y$ cell lines after $24 \mathrm{~h}$ of incubation using MTT and $\mathrm{LDH}$. In the control samples, $0.005 \%$ of $\mathrm{NaOH}$ was added to cells as a damaging reagent: (a) The cell viability percentage while treated with $\alpha$-Syn pre-incubated with altered concentrations of nanoliposome after $24 \mathrm{~h}$ of incubation using MTT assay, and (b) Cell membrane integrity evaluation using LDH assay for the cells treated with pre-incubated $\alpha$-Syn along with different concentrations of nanoliposome. Cytotoxicy percentages of $\alpha$-Syn pre-incubated with different concentrations of nanoliposome were normalized to that of $\alpha$-Syn pre-incubated alone, and the outcome was significantly different $(* p \leq 0.05)$.

There are some controversial debates concerning the toxicity of different aggregate species of proteins. Numerous studies have been reported that the presence of early aggregate species, known as oligomers, would lead to cell death. With respect to this fact, some are advocates for a theory that inhibition of the fibrillation procedure can lead to the prevention of cell death and disease progress [11], whereas others believe that induction of oligomers towards mature fibrils modulates cell degeneration. Based on the latter, nanoparticles, especially those that possess an ability to accelerate
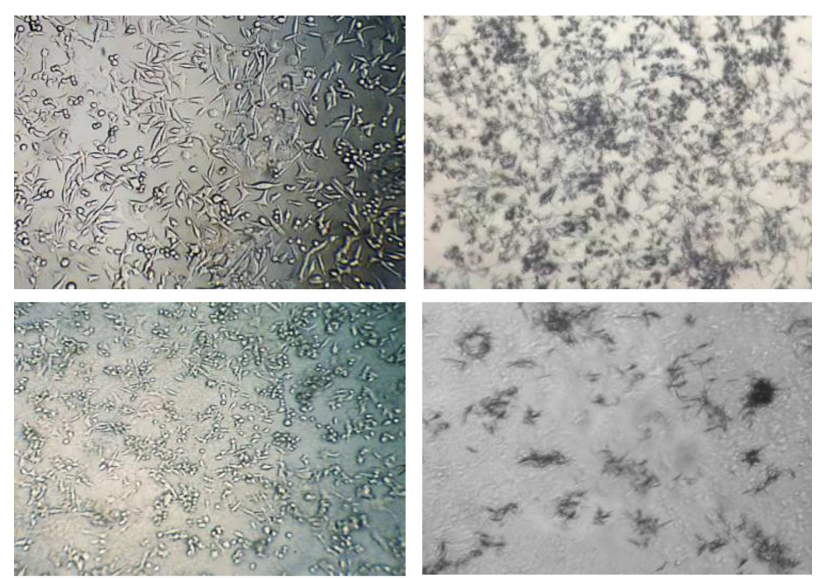

(a)
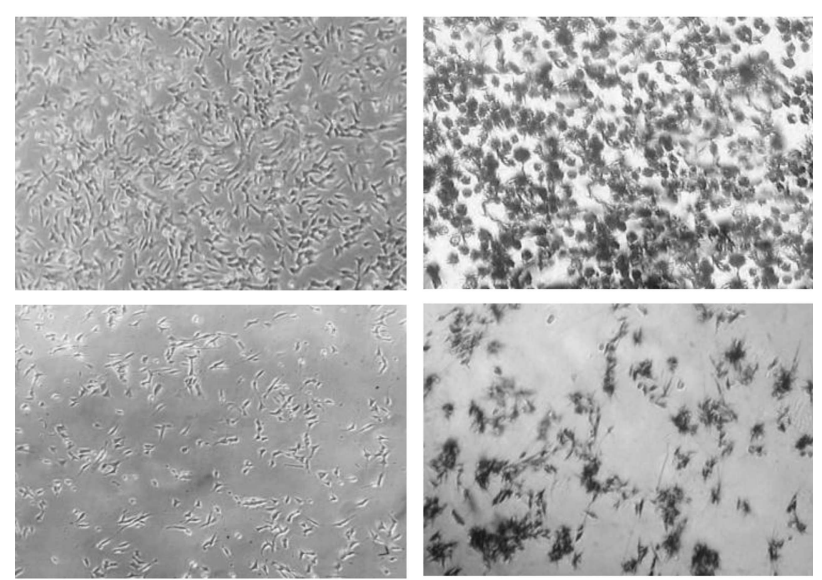

(b)

Figure 6. (a) Images of PC12, (b) SHSY5Y cells. Morphology of the cells (left) and crystals of formazan (right) is shown in the figure. In each part, the upper and lower images are indicated for control cells and the cells treated with incubated $\alpha$-Syn for $24 \mathrm{~h}$, respectively.

fibrillation, would be proper candidates to reduce oligomers, and consequently hinder cell death [26]. Furthermore, a recent study has suggested that the trend of fibrillation and aggregation process plays a crucial role in cell toxicity, and inhibiting fibril growth and seeding aptitude may act as a viable strategy to protect cells from degeneration [10]. Finally, according to the existing conflicts, more investigations are required to elucidate the mechanism of $\alpha$-Syn pathologic species and its impact on cell death while being treated by nanoparticles.

\section{Conclusion}

At present, engineered nanoparticles are recognized as promising and mighty tools to control or treat neurodegenerative diseases if their safety, biocompatibility, and biodegradability can be addressed. In this report, we have evaluated the toxicity of nanoliposomes formulated with neutral charge towards two dopaminergic 
cell lines including PC12 and SHSY5Y. The effect of nanoliposomes on $\alpha$-Syn aggregation has been also assessed. Our results showed that the nanoliposomes formulated from DPPC with neutral charge have no neurotoxic effect on the cell lines applied here and can additionally prevent $\alpha$-Syn fibrillation. Nanoliposomes pre-incubated with $\alpha$-Syn could, in turn, decrease the cell toxicity, confirming nanoliposomes benefits in curing amyloid-related disease. It is clear from the current study that nanoliposomes can be perceived as a potent nano carrier with no neurotoxicity to transfer small molecules, which have the potential to inhibit fibril formation in the treatment of PD and other synucleinopathy diseases.

\section{Acknowledgements}

This work was financially supported by the Student Research Committee of Semnan University of Medical Sciences, Semnan, Iran (Grant No. 832, Code of Ethics Committee: IR.SEMUMS.REC.1394.24), and the National Institute of Genetic Engineering and Biotechnology, Tehran, Iran (Grant No. 832, Code of ethics Committee: IR.SEMUMS.REC.1394.24). We would like to thank the Research Center of Biotechnology of Semnan University of Medical Sciences Institute as well as Industrial and Environmental Biotechnology of National Institute of Genetic Engineering and Biotechnology for their cooperation and providing facilities to this work.

\section{Abbreviations}

$\alpha$-Syn Alpha-Synuclein

PD Parkinson's Disease

DPPC Dipalmitoylphosphatidylcholine

AD Alzheimer's Disease

ThT Thioflavin $\mathrm{T}$

MTT 3-(4,5-dimethylthiazol-2-yl)-2,5diphenyltetrazolium bromide

MVV Multivesicular Vesicles

MLV Multilamellar Vesicles

LUV Large Unilamellar Vesicles

SUV Small Unlilamellar Vesicles

TEM Transmission Electron Microscopy

LDH Lactate dehydrogenase

\section{References}

1. Luheshi, L.M. and Dobson, C.M. "Bridging the gap: from protein misfolding to protein misfolding diseases", FEBS. Lett., 583(16), pp. 2581-2586 (2009).

2. Eisenberg, D. and Jucker, M. "The amyloid state of proteins in human diseases", Cell, 148, pp. 1188-203 (2012).
3. Maroteaux, L., Campanelli, J.T. and Scheller, R.H. "Synuclein: A neuron-specific protein localized to the nucleus and presy-naptic nerve terminal", J. Neurosci., 8, pp. 2804-2815 (1988).

4. Jakes, R., Spillantini, M.G. and Goedert, M. "Identification of two distinct synucleins from human brain", FEBS Lett., 345, pp. 27-32 (1994).

5. Goedert, M. "Parkinson's disease and other alphasynucleinopathies", Clin. Chem. Lab. Med., 39, pp. 308-312 (2001).

6. Zarranz, J.J., Alegre, J., Gomez-Esteban, J.C., Lezcano, E., Ros, R., Ampuero, I., Vidal, L., Hoenicka, J., Rodriguez, O., Atares, B., Llorens, V., Gomez Tortosa, E., del Ser, T., Munoz, D.G. and de Yebenes, J.G. "The new mutation, E46K, of alpha-synuclein causes Parkinson and Lewy body dementia", Ann. Neurol., 55, pp. 164-73 (2004).

7. Wu, C.K. "Parkinson's disease with dementia, lewybody disorders and alpha-synuclein: recent advances and a case report", Acta. Neurol. Taiwa., 20, pp. 4-14 (2011).

8. Spillantini, M.G., Schmidt, M.L., Lee, V.M., Trojanowski, J.Q., Jakes, R. and Goedert, M. "Alphasynuclein in Lewy bodies", Nature, 388, pp. 839-840 (1997).

9. Recasens, A., Dehay, B., Bove, J., Carballo-Carbajal, I., Dovero, S., Perez-Villalba, A., Fernagut, P.O., Blesa, J., Parent, A., Perier, C., Farinas, I., Obeso, J.A., Bezard, E. and Vila, M. "Lewy body extracts from Parkinson disease brains trigger alpha-synuclein pathology and neurodegeneration in mice and monkeys", Ann. Neurol., 75, pp. 351-352 (2014).

10. Mahul-Mellier, A.L., Vercruysse, F., Maco, B., AitBouziad, N., De Roo, M., Muller, D. and Lashuel, H.A. "Fibril growth and seeding capacity play key roles in $\alpha$-Syn-mediated apoptotic cell death", Cell. Death. Differ., 22(12), pp. 2107-2122 (2015).

11. Morshedi, D., Salmani Kesejini, T., Aliakbari, F., Karami-Osboo, R., Shakibaei, M., Tayaranian Marvian, A., Khalifeh, M. and Soroosh, M. "Identification and characterization of a compound from Cuminum cyminum essential oil with antifibrillation and cytotoxic effect", RPS., 9, pp. 431-443 (2014).

12. Breydo, L., Newland, B., Zhang, H., Rosser, A., Werner, C., Uversky, V.N. and Wang, W. "A hyperbranched dopamine-containing PEG-based polymer for the inhibition of $\alpha$-Syn fibrillation", Annu. Rev. Phys. Chem., 469(4), pp. 830-835 (2016).

13. Temsamani, H., Krisa, S., Decossas-Mendoza, M., Lambert, O., Mérillon, J.M. and Richard, T., "Piceatannol and other wine stilbenes: A pool of inhibitors against $\alpha$-Syn aggregation and cytotoxicity", Nutrients, 8(6), p. 367 (2016).

14. Adiseshaiah, P.P., Hal, J.B. and McNeil, S.E. "Nanomaterial standards for efficacy and toxicity assessment", Wiley. Interdiscip. Rev. Nanomed. Nanobiotechnol., 2(1), pp. 99-112 (2010). 
15. Sajja, H.K., East, M.P., Mao, H., Wang, Y.A., Nie, S. and Yang, L. "Development of multifunctional nanoparticles for targeted drug delivery and noninvasive imaging of therapeutic effect", Curr. Drug. Discov. Technol., 6(1), p. 43 (2009).

16. Nel, A.E., Mädler, L., Velegol, D., Xia, T., Hoek, E.M.V., Ponisseril Somasundaran, P., Klaessig, F., Castranova, V. and Thompson, M. "Understanding biophysicochemical interactions at the nano-bio interface", Nat. Mater., 8(7), pp. 543-557 (2009).

17. Lehner, R., Wang, X., Marsch, S. and Hunziker, P. "Intelligent nanomaterials for medicine: carrier platforms and targeting strategies in the context of clinical application", Nanomedicine: N.B.M., 9(6), pp. 742-757 (2013).

18. Akbarzadeh, A., Rezaei-Sadabady, R., Davaran, S., Woo Joo, S., Zarghami, N., Hanifehpour, Y., Samiei, Kouhi, M. and Nejati-Koshki K. "Liposome: classification, preparation, and applications", Nanoscale Res Lett., 8(1), p. 102 (2013).

19. Veiga, G.C. "Liposomes as versatile tools: nanoreactors, membrane models and drug delivery carriers", Doctoral Thesis Department of Chemical Engineering, University Rovira i Virgili Tarragona, Spain. T, pp. 154-2015 (2015).

20. Galvagnion, C., Buell, A.K., Meisl, G., Michaels, T.C., Vendruscolo, M., Knowles, T.P. and Dobson, C.M. "Lipid vesicles trigger alpha-synuclein aggregation by stimulating primary nucleation", Nat. Chem. Biol., 11, pp. 229-234 (2015).

21. Liu, Q., Zhang, J., Sun, W., Xie, Q.R., Xia, W. and $\mathrm{Gu}, \mathrm{H}$. "Delivering hydrophilic and hydrophobic chemotherapeutics simultaneously by magnetic mesoporous silica nanoparticles to inhibit cancer cells", Int J. Nanomedicine, 7, pp. 999-1013 (2012).

22. Vazzana, M., Andreani, T., Fangueiro, J., Faggio, C., Silva, C., Santini, A., Garcia, M.L., Silva, A.M. and Souto, E.B. "Tramadol hydrochloride: Pharmacokinetics, pharmacodynamics, adverse side effects, coadministration of drugs and new drug delivery systems", Biomed Pharmacother., 70, pp. 234-238 (2015).

23. Nogueira, E., Gomes, A.C., Preto, A. and CavacoPaulo, A. "Design of liposomal formulations for cell targeting", Colloids. Surf. B. Biointerfaces, 136, pp. 514-526 (2015).

24. Suzuki, R., Omata, D., Oda, Y., Unga, J., Negishi, Y. and Maruyama, K. "Cancer therapy with nanotechnology-based drug delivery systems: applications and challenges of liposome technologies for advanced cancer therapy", Nanomater in Pharmacol., pp. 457-482 (2016).

25. Klajnert, B., Wasiak, T., Ionov, M., FernandezVillamarin, M., Sousa-Herves, A., Correa, J., Riguera, R. and Fernandez-Megia, E. "Dendrimers reduce toxicity of A $\beta$ 1-28 peptide during aggregation and accelerate fibril formation", Nanomedicine, 8(8), pp. 13721378 (2012).
26. Mohammad-Beigi, H., Shojaosadati, S.A., Marvian, A.T., Pedersen, J.N., Klausen, L.H., Christiansen, G., Pedersen, J.S., Dong, M., Morshedi, D. and Otzen, D.E. "Strong interactions with polyethyleniminecoated human serum albumin nanoparticles (PEI-HSA NPs) alter $\alpha$-synuclein conformation and aggregation kinetics", Nanoscale, 7(46), pp. 19627-19640 (2015).

27. Chopra, D., Gulati, M., Saluja, V., Pathak, P. and Bansal, P. "Brain permeable nanoparticles", Recent Patents CNS Drug Discov., 3, pp. 216-225 (2008).

28. Masuda-Suzukake, M., Nonaka, T., Hosokawa, M., Oikawa, T., Arai, T., Akiyama, H., Mann, D.M. and Hasegawa, M. "Prion-like spreading of pathological alpha-synuclein in brain", Brain, 136, pp. 1128-1138 (2013).

29. Reyes, J.F., Olsson, T.T., Lamberts, J.T., Devine, M.J., Kunath, T. and Brundin, P. "A cell culture model for monitoring alpha-synuclein cell-to-cell transfer", Neurobiol Dis., 77, pp. 266-275 (2014).

30. Dua, J.S., Rana, A.C. and Bhandari, A.K. "Liposome: methods of preparation and applications", Int. J. Pharm. Stud. Res., 3, pp. 14-20 (2012).

31. Lorenzen, N., Lemminger, L., Pedersen, J.N., Nielsen, S.B. and Otzen, D.E. "The N-terminus of $\alpha$-synuclein is essential for both monomeric and oligomeric interactions with membranes", FEBS Let., 588(3), pp. 497502 (2014).

32. Polymeropoulos, M.H., Lavedan, C., Leroy, E., Ide, S.E., Dehejia, A., Dutra, A., Pike, B., Root, H., Rubenstein, J., Boyer, R., Stenroos, E.S., Chandrasekharappa, S., Athanassiadou, A., Papapetropoulos, T., Johnson, W.G., Lazzarini, A.M., Duvoisin, R.C., Di Iorio, G., Golbe, L.I. and Nussbaum, R.L. "Mutation in the alpha-synuclein gene identified in families with Parkinson's disease", Science, 276, pp. 2045-2047 (1997).

33. Bellotti, V., Nuvolone, M., Giorgetti, S., Obici, L., Palladini, G., Russo, P., Lavatelli, F., Perfetti, V. and Merlini, G. "The workings of the amyloid diseases", Ann. Med., 39, pp. 200-207 (2007).

34. Petrucci, S., Ginevrino, M. and Valente, E.M. "Phenotypic spectrum of alpha-synuclein mutations: new insights from patients and cellular models", Park. Relat. Disord., 22, pp. 16-20 (2016).

35. Jucker, M. "The benefits and limitations of animal models for translational research in neurodegenerative diseases", Nat Med., 16, pp. 1210-1214 (2010).

36. Jucker, P.M. and Walker, L.C. "Self-propagation of pathogenic protein aggregates in neurodegenerative diseases", Nature, 501, pp. 45-51 (2013).

37. Glabe, C.G. "Conformation-dependent antibodies target diseases of protein misfolding", Trends Biochem Sci., 29, pp. 42-547 (2004).

38. Wang, S.S., Chen, Y.T. and Chou, S.W. "Inhibition of amyloid fibril formation of beta-amyloid peptides via the amphiphilic surfactants", Biochim. Biophys. Acta., 1741, pp. 307-313 (2005). 
39. Morshedi, D., Salmani Kesejini, T., Aliakbari, F., Karami-Osboo, R., Shakibaei, M., Tayaranian Marvian, A., Khalifeh, M. and Soroosh, M. "Identification and characterization of a compound from Cuminum cyminum essential oil with antifibrilation and cytotoxic effect", Res. Pharm. Sci., 9(6), pp. 431-443 (2014).

40. Temsamani, H., Krisa, S., Decossas-Mendoza, M., Lambert, O., Mérillon, J.M. and Richard, T. "Piceatannol and other wine stilbenes: A pool of inhibitors against $\alpha$-synuclein aggregation and cytotoxicity", Nutrients, 8(6), p. 367 (2016).

41. Kampinga, H.H. and Bergink, S. "Heat shock proteins as potential targets for protective strategies in neurodegeneration", The Lancet Neurol., 15(7), pp. 748759 (2016).

42. Bastus, N.G., Kogan, M.J., Amigo, R., Grillo-Bosch, D., Araya, E., Turiel, A., Labarta, A., Giralt, E. and Puntes, V.F. "Gold nanoparticles for selective and remote heating of $\beta$-amyloid protein aggregates", Mater. Sci. Eng. C., 27, pp. 1236-1240 (2007).

43. Choi, J.-S., Choi, H.J., Jung, D.C., Lee, J.-H. and Cheon, J. "Nanoparticle assisted magnetic resonance imaging of the early reversible stages of amyloid [small beta] self-assembly", Chem. Commun., pp. 2197-2199 (2008).

44. Linse, S., Cabaleiro-Lago, C., Xue, W.-F., Lynch, I., Lindman, S., Thulin, E., Radford, S.E. and Dawson, K.A. "Nucleation of protein fibrillation by nanoparticles", Proc. Natl. Acad. Sci., 104, pp. 8691-8696 (2007).

45. Fei, L. and Perrett, S. "Effect of nanoparticles on protein folding and fibrillogenesis", Int J Mol Sci., 10(2), pp. 646-655 (2009).

46. Zaman, M., Ahmad, E., Qadeer, A., Rabbani, G. and Khan, R.H. "Nanoparticles in relation to peptide and protein aggregation", Int. J. Nanomedicine., 9, p. 899 (2014).

47. Jones, O.G. and Mezzenga, R. "Inhibiting, promoting, and preserving stability of functional protein fibrils", Soft. Matter., 8, pp. 876-895 (2012).

48. Lin, H., Patel, S., Affleck, V.S., Wilson, I., Turnbull, D.M., Joshi, A.R., Maxwell, R. and Stoll, E.A. "Fatty acid oxidation is required for the respiration and proliferation of malignant glioma cells", Neuro Oncol., p. 128 (2016).

49. Savolainen, K., Alenius, H., Norppa, H., Pylkkänen, L., Tuomi, T. and Kasper, G. "Risk assessment of engineered nanomaterials and nanotechnologies-a review", Toxicology, 269(2-3), pp. 92-104 (2010).

50. Loo, S.C., Moore, T., Banik, B. and Alexis, F. "Biomedical applications of hydroxyapatite nanoparticles", Curr. Pharm. Biotechnol., 11(4), pp. 333-342 (2010).

51. Nel, A., Xia, T., Mädler, L. and Li, N. "Toxic potential of materials at the nanolevel", Science, 311(5761), pp. 622-627 (2006).
52. Fröhlich, E. "The role of surface charge in cellular uptake and cytotoxicity of medical nanoparticles", Int. J. Nanomedicine, 7, pp. 5577-5591 (2012).

53. Petushkov, A., Intra, J., Graham, J.B., Larsen, S.C. and Salem, A.K. "Effect of crystal size and surface functionalization on the cytotoxicity of silicalite-1 nanoparticles", Chem. Res. Toxicol., 22(7), pp. 13591368 (2009).

54. Filion Mario, C. and Phillips Nigel, C. "Toxicity and immunomodulatory activity of liposomal vectors formulated with cationic lipids toward immune effector cells", Biochim Biophys Acta., 1329, pp. 345-356 (1997).

55. Campbell, P.I. "Toxicity of some charged lipids used in liposome preparations", Cytobios, 37, pp. 21-26 (1983).

56. Dokka, S., Toledo, D., Shi, X., Castranova, V. and Rojanasakul, Y. "Oxygen radical-mediated pulmonary toxicity induced by some cationic liposomes", Pharm. Res., 17, pp. 521-525 (2000).

57. Nagahiro, I., Mora, B.N., Boasquevisque, C.H.R., Scheule, R.K. and Patterson, G.A. "Toxicity of cationic liposome - DNA complex in lung isografts", Transplantation, 69, pp. 1802-1805 (2000).

58. Krasnici, S., Werner, A., Eichhorn, M.E., SchmittSody, M., Pahernik, S.A., Sauer, B., Schulze, B., Teifel, M., Michaelis, U., Naujoks, K. and Dellian, M. "Effect of the surface charge of liposomes on their uptake by angiogenic tumor vessels", Int. J. Cancer., 105(4), pp. 561-567 (2003).

59. Smistad, G., Jacobsen, J. and Sande, S.A. "Multivariate toxicity screening of liposomal formulations on a human buccal cell line", Int. J. Pharm., 330, pp. 1422 (2007).

\section{Biographies}

Farhang Aliakbari has been a Research Assistant at National Institute of Genetic Engineering and Biotechnology (NIGEB). He is now a researcher at Semnan University of Medical Sciences and NIGEB carrying out research on the interaction of $\alpha$-Syn with nanoliposomes and their neurotoxicity.

Ali Akbar Shabani received his $\mathrm{PhD}$ in Medical Biotechnology from Pasteur Institute (2001). He is now an Assistant Professor and the Head of the Department and Center for biotechnology research at Semnan University of Medical Sciences. His research focuses on different aspect of biological products especially Beta hCG in mammalian cells.

Hassan Bardania received his $\mathrm{PhD}$ in Nanobiotechnology from Tarbiat Modares University (2016). He is now an Assistant Professor in the Cellular and 
Molecular Research Center at Yasuj University of Medical Sciences. His research group pursues applicationoriented research on drug delivery using nanoliposomes and metal nanoparticles.

Hadieh Alsadat Eslampanah Seyedi graduated with a master degree at Isfahan University of Technology (IUT). She was a Research Assistant at NIGEB. Currently, she is a PhD student in the field of Molecular Biology and Biochemistry at Institute for Glycomics, Griffith University, QUL, Australia.

Hossein Mohammad-Beigi received his $\mathrm{PhD}$ in Chemical Engineering-Biotechnology from Tarbiat Modares University (2015). He is now a Guest Researcher at Aarhus University, Denmark. His research focuses on the amyloid proteins and the interaction between these proteins with nanoparticles.

Amir Tayaranian Marvian graduated with master degree from Tehran University in the field of Molecular and Cellular Biology. He was a Research Assistant at NIGEB and now he is PhD student at the Technical University of Munich, Germany. His research area focuses on the pathology of the amyloid protein especially alpha-synuclein and Tau.

Mahour Nassoti graduated with master degree at NIGEB in the field of Molecular and Cellular Biology. Her research was focused on the effect of small molecules on differentiated neuronal cells.

Abbas Ali Vafaei received his $\mathrm{PhD}$ in Physiology from Isfahan University of Medical Sciences (2000). He is now a Professor of Physiology at Semnan University of Medical Sciences. His research realm is on Parkinson's disease and the mechanism of cell death in such a disease.

Seyed Abbas Shojaosadati received his $\mathrm{PhD}$ in Chemical Engineering from Birmingham University (1988). He now is a Professor and the Head of Chemical Engineering Department at Tarbiat Modares University. His research focuses on the nano-biotechnology.

Ali Akbar Saboury received his $\mathrm{PhD}$ in Physical Chemistry from Tarbiat Modares University (1996). $\mathrm{He}$ is now a Professor at the Institute of Biochemistry and Biophysics (IBB), University of Tehran. His research realm is on the thermodynamic aspects of protein denaturation with the aim of obtaining additional information regarding protein structure-function relationship.

Gunna Christiansen passed her Internship in Internal Medicine and Surgery in 1969. She received her Doctor of Medical Science (D.M.Sc.) on Electron microscopy of nucleic acids in 1987. She is a Professor of Medical Molecular Biology at the Department of Medical Microbiology and Immunology, University of Aarhus, Denmark.

Dina Morshedi received her $\mathrm{PhD}$ in Biochemistry from Institute of Biochemistry and Biophysics (IBB) (2008), University of Tehran. She is now an Assistant Professor at NIGEB. Her research realm is protein folding and miss folding. She works on the role of $\alpha$-Synuclein in the process of neurodegeneration in Parkinson's disease and using nanoparticles for drug delivery in such a disease. 